\title{
Monooxygenase Levels and Knockdown Resistance (kdr) Allele Frequencies in Anopheles gambiae and Anopheles arabiensis in Kenya
}

\author{
Hong Chen ${ }^{1}$, Andrew K Githeko ${ }^{2}$, John I Githure ${ }^{3}$, James Mutunga ${ }^{3}$, Guofa Zhou ${ }^{1}$, and \\ Guiyun Yan ${ }^{1}$ \\ ${ }^{1}$ Program in Public Health, College of Health Sciences, University of California, Irvine, CA 92697, \\ USA \\ ${ }^{2}$ Kenya Medical Research Institute, P.O. Box 1578, Kisumu, Kenya \\ ${ }^{3}$ Human Health Division, International Centre of Insect Physiology and Ecology, Nairobi, Kenya
}

\section{Abstract}

Pyrethroid-treated bed nets and indoor spray are important components of malaria control strategies in Kenya. Information on resistance to pyrethroid insecticides in Anopheles gambiae and $A n$. arabiensis populations is essential to the selection of appropriate insecticides and the management of insecticide resistance. Monooxygenase activity and knockdown resistance $(k d r)$ allele frequency are biochemical and molecular indicators of mosquito resistance to pyrethroids. This study determined baseline information on monooxygenase activity and $k d r$ allele frequency in anopheline mosquitoes in the western region, the Great Rift Valley-central province region, and the coastal region of Kenya. A total of 1990 field-collected individuals, representing $12 \mathrm{An}$. gambiae and 22 An. arabiensis populations was analyzed. We found significant among-population variation in monooxygenase activity in An. gambiae and An. arabiensis and substantial variability among individuals within populations. Nine out of 12 An. gambiae populations exhibited significantly higher average monooxygenase activity than the susceptible Kisumu reference strain. The $k d r$ alleles (L1014S) were detected in three An. gambiae populations, and one An. arabiensis population in western Kenya, but not in the Rift Valley-central region and the coastal Kenya region. All genotypes with the $k d r$ alleles were heterozygous, and the conservative estimation of $k d r$ allele frequency was below $1 \%$ in these four populations. Information on monooxygenase activity and $k d r$ allele frequency reported in this study provided baseline data for monitoring insecticide resistance changes in Kenya during the era when large-scale insecticide-treated bednet and indoor residual spray campaigns were being implemented.

\section{Keywords \\ Anopheles gambiae; Anopheles arabiensis; monooxygenase; $k d r$, insecticide resistance; Kenya}

\section{Introduction}

Insecticide-based vector control is a key tactic in the control and prevention of malaria, which results in 500 million clinical cases and one million deaths annually, with more than 90\% of deaths occurring in sub-Saharan Africa (Greenwood and Mutabingwa 2002).

Corresponding author address: Dr. Hong Chen, Program in Public Health, University of California at Irvine, Irvine, CA 92697, entomail@gmail.com, Tel: (949) 824 0249, Fax: (949) 8240249. 
Inexpensive insecticides such as DDT and dieldrin, used for indoor residual spray during the global malaria eradication campaign in the 1950s and 1960s, were initially very effective in many countries, including Kenya (Shanks et al. 2005). However, the effectiveness of DDT and dieldrin was not sustained, partially because of the emergence of resistance to the insecticides in the mosquito vectors (Akogbeto et al. 2006). Since the 1990s, pyrethroids have been promoted as insecticides of choice for bed net impregnation and indoor spray (WHO 1993) due to their high efficacy, rapid rate of knockdown, strong mosquito excitorepellency, and low mammalian toxicity (WHO 1993, Hemingway et al. 2004, Liu et al. 2006). As demonstrated in multi-site trials throughout Africa, the large-scale use of insecticide-treated bed nets (ITNs) reduces childhood malaria morbidity by up to $50 \%$ and overall mortality by 20-30\% in Gambia, Ghana, and Kenya (Alonso et al. 1991, Binka et al. 1996, Nevill et al. 1996, Phillips-Howard et al. 2003).

Consequently, WHO recommends the large-scale use of ITNs to control malaria transmission because ITNs offer a good cost-effective method based on active community involvement (Wiseman et al. 2003). Currently, pyrethroid-treated bed nets and indoor spray are the central components in the Global Strategy for Malaria Control and the Roll Back Malaria program which was launched in 1998 (WHO 1993, Yamey 2004), and more recently in the malaria control program funded by the Global Fund to Fight against AIDS, Tuberculosis and Malaria (GFATM 2007). With increased use of pyrethroid insecticides for malaria vector control in Africa, resistance to pyrethroids was reported in the major African malaria vectors, including Anopheles gambiae in Benin, Burkina Faso, Ivory Coast, Kenya and Mozambique (Elissa et al. 1993, Vulule et al. 1994, Curtis et al. 1998, Chandre et al. 1999, Casimiro 2006a), and An. funestus in Mozambique and South Africa (Hargreaves et al. 2000, Brooke et al. 2001, Casimiro et al. 2006b). The distribution of mosquito resistance is uneven, with greater resistance reported in western and southern Africa than in eastern Africa.

Anopheline mosquitoes exhibit two major mechanisms of pyrethroid resistance through an increased level of metabolic detoxification of the insecticide and reduced sensitivity in the target sites of the insecticide. Metabolic detoxification is generally associated with increased monooxygenase activity, causing not only pyrethroid resistance but also cross-resistance to unrelated compounds (Berge et al. 1998, Liu et al. 2006). The target site of pyrethroids is the voltage-gated sodium channel. A point mutation in the region II of the para-type sodium channel gene causes a change in affinity between the insecticide and its binding site on the sodium channel, and induces a phenotype termed knockdown resistance $(k d r)$ in a range of insects (Williamson et al. 1996, Dong 1997, Jamroz et al. 1998, Martinez-Torres et al. 1998, 1999, Ranson et al. 2000). Insensitivity at the sodium channel target sites also leads to crossresistance between different classes of insecticides (Brengues et al. 2003). Permethrin knock-down resistance has arisen independently at least twice in Africa. In west Africa, $k d r$ was caused by a leucine-phenylalanine substitution at position 1014 of the sodium channel gene (L1014F) whereas a different mutation (leucine-serine substitution) at the same amino acid position (L1014S) was associated with $k d r$ resistance in Kenya in both $A$. gambiae and A. arabiensis (Martinez-Torres et al. 1998; Ranson et al. 2000; Stump et al. 2004). However, the L1014F mutation has been detected in An. gambiae and An. arabiensis in Tanzania and Uganda (Kulkarni et al. 2006, Verhaeghen et al. 2006). Interestingly, both L1014F and L1014S mutations were detected in the An. gambiae mosquitoes from Libreville in Gabon, and the L1014S mutation exhibited a higher frequency than L1014F (Pinto et al. 2006).

The objective of the present study is to determine broad-scale baseline information on pyrethroid resistance in major malaria vectors in Kenya. Malaria vectors could be exposed to selection by insecticides through previous insecticide usage for agricultural or public health pest control. Thus, information on the current resistance level is valuable in predicting 
the rate of pyrethroid resistance increase in the era of large-scale use of pyrethroid insecticides for malaria vector control, and in designing appropriate strategies to manage the resistance. We used mosquito monooxygenase levels and $k d r$ allele frequency as resistance surrogates. Mosquito resistance as detected by biochemical assays could be influenced by age, blood feeding, sex, body size and other physiological statuses such as pre-exposure to insecticides and matting (Vulule et al. 1999, Hunt et al. 2005, Casimiro et al. 2006a, b, Matambo et al. 2007). Therefore, in this study, we first determined the effects of age and bloodfeeding on individual monooxygenase levels in a susceptible Anopheles gambiae strain because this enzyme is expressed as equivalent units of cytochrome P450. With the established methods of biochemical measurement and PCR detection, we determined the baseline information on monooxygenase levels and $k d r$ allele frequencies of An. gambiae and $A n$. arabiensis populations in three ecological and epidemiologically different zones in Kenya.

\section{Materials and Methods}

\section{Study areas and specimen collection}

Between April and June 2005, mosquito larvae were collected from 34 sites in the three geographically and epidemiologically distinct regions, the western region (16 sites), the Great Rift Valley and central region (12 sites) and the coastal region (6 sites) in Kenya (Fig. 1). In western Kenya, particularly the basin region of Lake Victoria, malaria transmission is perennial, and transmission intensity measured by entomological inoculation rate (EIR) is typically in the order of several dozens to several hundreds infectious bites per person per year, and Anopheles gambiae is the predominant malaria vector (Chen et al. 2004, Shanks et al. 2005). Malaria transmission in the Great Rift Valley is seasonal, An. arabiensis is the predominant malaria vector, and An. gambiae has not been reported in the region (Lehmann et al. 2003, Nyanjom et al. 2003, Temu and Yan 2005). In the central region, malaria transmission is sporadic, and An. arabiensis is also the predominant malaria vector (Chen et al. 2006a). Malaria transmission in coastal Kenya is perennial, but transmission intensity is generally much lower than in western Kenya, and An. gambiae is the predominant malaria vector species (Mbogo et al. 2003).

Larvae of An. gambiae s. 1 . were collected using the standard 250ml dippers, kept in plastic bottles, and transported to an insectary closer to a collection site. The collection sites are categorized into five types: small pond (created by rain or spring water of several square meters and no full coverage of aquatic plants), big pond (standing water body of more than $50 \mathrm{~m}^{2}$ without full coverage of aquatic plants), swamp (various sizes of water bodies with high density of aquatic plants), footprints (animal or human footprints with rain water) and swimming pool (drained concrete pool with shallow rain water at the bottom). Larvae were reared to adults with TetraMin ${ }^{\circledR}$ fish food for quantification of monooxygenase activities. The global coordinates of all collection sites were recorded using a handheld GPS unit. We did not collect adult female mosquitoes from the field because the measurement of monooxygenase activity may be strongly affected by mosquito age that can not be determined reliably.

A susceptible laboratory colony of An. gambiae s.s. (the WHO-referenced Kisumu strain; Vulule et al. 1996, 1999) was used to establish baseline enzyme activities in susceptible mosquitoes, and to determine whether the monooxygenase activity in adult mosquitoes varied by age and food types. One-day-old female adult mosquitoes were divided into two groups. Group one was fed with $6 \%$ sucrose solution for $30 \mathrm{~min}$, then maintained on water without sucrose (sugar-fed group). Group two was exposed to restrained rabbits for $30 \mathrm{~min}$; only fully engorged mosquitoes were maintained on water without sucrose and used for 
monooxygenase activity measurement (blood-fed group). Twenty five to 30 female mosquitoes of the Kisumu strain were tested for monooxygenase activity every $1-2$ days.

\section{Monooxygenase quantification}

Monooxygenase activity was measured in individual female mosquitoes, using the method described by Brengues et al. (2003) with a slight modification. Briefly, a substrate solution of 7-ethoxycoumarine (7EC) $(20 \mathrm{mM})$ was prepared in ethanol, and $20 \mu \mathrm{l}$ of the 7EC solution was added to $1 \mathrm{ml}$ of phosphate buffer $(50 \mathrm{mM}, \mathrm{pH}$ 7.2) containing $1 \mathrm{mM}$ EDTA, $0.1 \mathrm{mM}$ dithiothreitol, $2 \mathrm{mM}$ 1-chloro-2, 4-dinitrobenzene and $0.1 \mathrm{mM}$ reduced glutathione. A single female was homogenized in a $0.5 \mathrm{ml}$ tube with $150 \mu \mathrm{l}$ of the 7EC buffer solution. After incubation at $30^{\circ} \mathrm{C}$ for $4 \mathrm{hr}$, the conversion reaction of 7EC to 7-hydroxycoumarine was stopped by adding $210 \mu \mathrm{l}$ of glycine buffer $(0.1 \mathrm{mM}, \mathrm{pH} 10.4)$. The solution was transferred into a cuvette without mosquito tissue, and optical density (OD) at $450 \mathrm{~nm}$ was measured using a SMART ${ }^{\circledR}$ Spectro Spectrophotometer (LaMotte Co., Chestertown, MD). The OD values were converted into concentration $(\mathrm{pg} / \mu \mathrm{l})$ using a standard regression based on a serial dilution of 7-hydroxycoumarine (Kasei Kogyo Co., Tokyo, Japan) and its relevant OD values. Forty to 90 adult females from field collections, at post-emergence ages of $7-10$ days, were tested for monooxygenase activity. We chose 7-10 day old adult mosquitoes for monooxygenase activity determination because the enzyme level was not stable in younger mosquitoes (see below). A total of 1990 individuals was analyzed and reported in this study. Mosquito tissue was preserved in $95 \%$ ethanol and kept at $-20{ }^{\circ} \mathrm{C}$ for subsequent DNA extraction and PCR detection of $k d r$.

\section{DNA extraction, species identification and $k d r$ detection}

Genomic DNA was extracted individually from the preserved mosquito tissue after monooxygenase measurement, following the previously described method (Chen et al. 2004, 2006b). Field collected samples within An. gambiae s. l. were further identified to species using the rDNA-PCR method described by Scott et al. (1993). If a sample could not be identified after three PCR amplifications, it was marked as unknown. The $k d r$ genotypes were determined for all specimens, using the allele-specific PCR assay described by Ranson et al. (2000). A total of 1990 individuals was tested for $k d r$ alleles.

\section{ND5 gene sequencing}

Because the above tested samples were collected at larval stage from one or several nearby aquatic sites at each location, there was a possibility that the resistant individuals from the same or several closely-located breeding sites may have been maternally related (Chen et al. 2006b). To determine the maternal relatedness of individuals with the $k d r$ allele, a 665-bp polymorphic fragment of the subunit 5 of the mitochondrial NADH dehydrogenase gene (ND5) was amplified using primer 19CL and DMP3A (Besansky et al. 1997), and sequenced from both ends using the ABI BigDye Sequencing kit (Applied Biosystems, Foster City, CA). A total of 39 An. gambiae individuals with the L1014S mutation in the sodium channel gene collected in three sites (Bondo, Mumias and Stendmwako) was sequenced.

\section{Data analyses}

The collection sites were mapped with ArcView 3.2 GIS software. The OD values of monooxygenase level were converted into concentration in picogram per minute per larva, based on the standard curve. One-way analysis of variance (ANOVA) with age as the factor was conducted for the laboratory Kisumu An. gambiae strain to determine whether monooxygenase activity varied with mosquito age. Monooxygenase activity data was square root transformed. The t-test was used for group comparison when appropriate. One-way 
ANOVA was also used to examine whether monooxygenase activity varied among the sampling sites for An. gambiae and An. arabiensis. The sampling site was treated as a random factor. Chi-square test was applied to test whether $k d r$ frequencies varied significantly among the sampling sites. The ND5 gene sequence data was aligned and haplotypes identified using the BioEdit software (Hall 1999).

\section{Results}

\section{Monooxygenase activity in the susceptible An. gambiae reference strain}

Monooxygenase activity varied significantly with mosquito age in both the sugar-fed $(\mathrm{F}=$ 5.62, $\mathrm{df}=12,289, \mathrm{P}<0.01)$ and blood-fed $(\mathrm{F}=8.44, \mathrm{df}=12,293, \mathrm{P}<0.01)$ groups of the susceptible Kisumu strain. The enzyme activity in certain mosquitoes increased dramatically 1 to 4 days post sugar or blood feeding, and then gradually decreased and remained temporally stable (Fig. 2). We termed the period of dramatic increase in monooxygenase activity of certain individuals the "stimulation phase", and the temporally less variable period the "stable phase". The sugar-fed group took 7 days to reach the stable phase whereas the blood-fed group took about 10 days (Fig. 2). The enzyme levels in the stimulation phases were significantly higher than those in the stable phases in both sugar-fed group $(\mathrm{t}=4.04$, $\mathrm{df}$ $=116, \mathrm{P}<0.01)$ and blood-fed group $(\mathrm{t}=6.43, \mathrm{df}=105, \mathrm{P}<0.01)$. Moreover, within each group, there was more variability in monooxygenase activity during the stimulation phase than the stable phase (Fig. 2). The sugar-fed and blood-fed groups did not differ significantly in the enzyme level in the stimulation phase $(\mathrm{t}=0.77, \mathrm{df}=206, \mathrm{P}=0.44)$ and stable phase $(\mathrm{t}=1.92, \mathrm{df}=336, \mathrm{P}=0.06)$, suggesting that the blood feeding did not affect monooxygenase activities.

\section{Monooxygenase levels in field-collected An. gambiae and An. arabiensis}

Using sugar-fed adults at 7-10 days post emergence (in the stable phase), we detected considerable within-population variations in monooxygenase activity for both wild $A n$. gambiae and An. arabiensis (Fig. 3). Such a large within-population variation contrasts the susceptible Kisumu An. gambiae reference strain. Both species exhibited significant amongsite variation in monooxygenase activity ( $A$. gambiae, $\mathrm{F}=80.85, \mathrm{df}=11,697, \mathrm{P}<0.001$; An. arabiensis, $\mathrm{F}=58.51, \mathrm{df}=21,1259, \mathrm{P}<0.001$ ). In particular, An. gambiae populations from Iguhu (west Kenya) and Tiwi (coastal Kenya) showed the highest values of monooxygenase activity ( $>90 \mathrm{pg} / \mathrm{min} / \mathrm{larva}$ ) while those from Mumias and Stendmwako (west Kenya) exhibited the lowest values ( $<30 \mathrm{pg} / \mathrm{min} / \mathrm{larva}$ ) (Fig. 3). An. arabiensis populations from Machakos (Rift Valley) had the highest monooxygenase levels (>90 pg/ $\mathrm{min} /$ larva) while those from Ahero and Kibigori (west Kenya) showed the lowest value (< $30 \mathrm{pg} / \mathrm{min} / \mathrm{larva}$ ) (Fig. 3). When compared to the susceptible Kisumu reference strain of the same age (sugar-fed, 7 and 9 day old), the field-collected An. gambiae at most sites exhibited substantially higher monooxygenase activity $(\mathrm{F}=80.10, \mathrm{df}=12,739, \mathrm{P}<0.001)$ except at Munias (Mu) and Malindi Green ( $\mathrm{Mg}$ ), where the An. gambiae enzyme activity showed no significant difference from that of the Kisumu strain, and at Stendmwako (St), where the An. gambiae enzyme activity was significantly lower than that of the Kisumu strain. Overall, monooxygenase activity in An. arabiensis from western Kenya was significantly lower than that from the Rift Valley-central region and coastal Kenya ( $\mathrm{F}=$ 129.07, df $=2,1278, \mathrm{P}<0.001)$.

\section{kdr allele frequencies in An. gambiae and An. arabiensis}

The L1014S- $k d r$ allele was detected in three An. gambiae populations and one An. arabiensis population from western Kenya (Table 2). All the $k d r$ alleles were presented in heterozygous states. The L1014S-kdr alleles were found in 39 out of 709 An. gambiae mosquitoes. Out of 1,281 An. arabiensis individuals tested, only one resistant allele in 
heterozygous state was detected in the Ahero population in western Kenya. Thus, the observed $k d r$ allele frequencies in An. arabiensis were significantly lower than in $A n$. gambiae in western Kenya $\left(\chi^{2}=10.22, \mathrm{df}=1, \mathrm{P}<0.01\right)$. L1014F- $k d r$ allele was not detected in any population.

Because the analysis of $k d r$ allele frequency was based on larval samples collected from larval habitats, the samples may have been be maternally related. We sequenced the 665-bp polymorphic region of ND5 for all 39 An. gambiae specimens with the L1014S- $k d r$ allele, and detected 6 polymorphic sites in two haplotypes (Table 3). Individuals with the $k d r$ allele from Mumias and Stendwako had the identical haplotype. Similarly, all individuals with the heterozygous $k d r$ genotype from Bondo showed a single haplotype. This result suggests that the $A n$. gambiae mosquitoes of $k d r$-genotype from one larval breeding site were likely produced by the same female. Therefore, the conservative estimate of $k d r$ allele frequency was < $1 \%$ in all sites for both An. gambiae and An. arabiensis (Table 2).

\section{Discussion}

This study examined monooxygenase activity and $k d r$ frequency distribution in the natural An. gambiae and An. arabiensis populations in western, Rift Valley-central, and coastal regions of Kenya because elevated monooxygenase activity and increased $k d r$ frequency in a population are associated with increased resistance to pyrethroids (Hemingway et al. 2004, Liu et al. 2006). We found significant variation in monooxygenase activity among the sampling sites in both species, and detected significant differences in the enzyme activity of $A n$. arabiensis across the three regions. In comparison to the susceptible Kisumu $A n$. gambiae strain, nine out of 12 An. gambiae field-collected populations exhibited significantly higher monooxygenase activity. The $k d r$ alleles were detected in three out of ten An. gambiae populations and one out of six An. arabiensis populations in western Kenya, but they were not observed in the Rift Valley and coastal Kenya.

In the present study, we collected anopheline larvae from natural habitats and reared them to adults for monooxygenase activity and $k d r$ frequency determination. The advantage of this approach was that all mosquito samples used in the biochemical test were at the same age, thus age was not a confounding factor for comparisons of monooxygenase activity among localities or for examination of enzyme activity variability among individuals within a population. This is important because in the time-course experiments with the susceptible laboratory An. gambiae colony, monooxygenase activity is age-dependent and less stable among young ( $<8$ days post emergence) mosquitoes than older ( $>9$ days post emergence) mosquitoes. Our time-course results on monooxygenase activity are consistent with the previous pyrethroid bioassays on An. gambiae and An. stephensi that the mean median knock-down times $\left(\mathrm{KT}_{50}\right)$ declined with mosquito age (Vulule et al. 1994; Hodjati and Curtis 1996). Interestingly, sugar feeding or blood feeding did not exhibit any significant effect on monooxygenase activity. Thus, to measure monooxygenase activity in natural mosquito populations, either blood-fed or sugar-fed mosquitoes can be used as long as their ages reach the stable phase (Fig. 2). The disadvantage of the approach is that some samples from the same habitat may be genetically related (Chen et al. 2006b), leading to over- or under-estimation of $k d r$ allele frequency. For example, in the current study, the observed $k d r$ allele frequencies were between $5-15 \%$ at three An. gambiae populations in western Kenya (Table 2). Since some $k d r$-allele individuals from an aquatic breeding site were likely from the same female, the conservative estimation of $k d r$ frequency should be less than $1 \%$. Several studies in western Africa An. gambiae populations found extremely high $k d r$ allele frequency based on larval samples (e.g., 20-96\% in Ivory Coast [Martinez-Torres et al. 1998], and 89-96\% in Burkina Faso [Diabate et al. 2002]). We recommend using adult 
samples or using larvae from many diverse aquatic habitats for insecticide resistance surveillance to minimize sampling bias.

In the present study, the low $k d r$ frequencies in multiple sites suggest that the selection pressure resulting from current and historic uses of insecticide for agricultural and public health pest control may not be high enough to induce the rise of $k d r$ allele frequency in $A n$. gambiae and An. arabiensis in Kenya. In the 1990s and early 2000s, insecticide-treated bednet (ITN) coverage in Kenya was generally low (Guyatt et al. 2004), and large-scale ITN coverage and indoor residual spray were primarily concentrated in bed net trial areas or well-organized vector control areas (e.g., Nevill et al. 1996; Bogh et al. 1998; Hawley et al. 2003, Lindblade et al. 2006). Our survey found that occasional agricultural insecticide use in Kenya was primarily in the rice, coffee/tea plantation and sugar cane growing areas while other areas reported little use of insecticides (Kamau and Vulule 2006). Stump et al. (2004) reported that the frequency of the $k d r$ allele in An. gambiae increased from 3-4\% to 4-8\% after 7-8 years of using pyrethroid-treated bednets in an ITN trial area in Asembo Bay, west Kenya. Therefore, intensive use of ITNs selected for increase of $k d r$ allele frequency. Information on monooxygenase activity and $k d r$ allele frequency reported in the present study provided baseline data for monitoring insecticide resistance changes in Kenya in the era of large-scale ITN coverage being implemented by the Global Fund to Fight against AIDS, Tuberculosis and Malaria (GFATM. 2007).

\section{Acknowledgments}

We thank M. Simiyu for technical assistance, and Drs. D. Amenya and C. Garros for comments on the manuscript. This research was supported by grants from NIH grant R01 AI50243 and the ICIDR Opportunity Pool Award. This paper has been published with the permission of the Director of KMRI.

\section{References Cited}

Akogbeto MC, Djouaka RF, Kinde-Gazard DA. Screening of pesticide residues in soil and water samples from agricultural settings. Malaria J. 2006; 5:22.

Alonso PL, Lindsay SW, Armstrong JR, Conteh M, Hill AG, David PH, Fegan G, de Francisco A, Hall AJ, Shenton FC, et al. The effect of insecticide-treated bed nets on mortality of Gambian children. Lancet. 1991; 337:1499-1502. [PubMed: 1675368]

Bergé JB, Feyereisen R, Amichot M. Cytochrome P450 monooxygenases and insecticide resistance in insects. Phi. Trans. Roy. Soc.: Bio. Sci. 1998; 353:1701-1705.

Besansky NJ, Lehmann T, Fahey GT, Fontenille D, Braack LEO, Hawley WA, Collins FH. Patterns of mitochondrial variation within and between African malaria vectors, Anopheles gambiae and An. arabiensis, suggest extensive gene flow. Genetics. 1997; 147:1817-1828. [PubMed: 9409838]

Binka FN, Kubaje A, Adjuik M, Williams LA, Lengeler C, Maude GH, Armah GE, Kajihara B, Adiamah JH, Smith PG. Impact of permethrin impregnated bednets on child mortality in KassenaNankana district, Ghana: a randomized controlled trial. Trop. Med. Int. Health. 1996; 1:147-154. [PubMed: 8665378]

Bogh C, Pederson EM, Mukoko DA, Ouma JH. Permethrin-impregnated bednet effects on resting and feeding behaviour of lymphatic filariasis vector mosquitoes in Kenya. Med. Vet. Entomol. 1998; 12:52-59. [PubMed: 9513939]

Brengues C, Hawkes NJ, Chandre F, Mccarroll L, Duchon S, Guillet P, Manguin S, Morgan JC, Hemingway J. Pyrethroid and DDT cross-resistance in Aedes aegypti is correlated with novel mutations in the voltage-gated sodium channel gene. Med Vet Entomol. 2003; 17:87-94. [PubMed: 12680930]

Brooke BD, Kloke G, Hunt RH, Koekemoer LL, Temu EA, Taylor ME, Small G, Hemingway J, Coetzee M. Bioassay and biochemical analyses of insecticide resistance in southern African Anopheles funestus (Diptera: Culicidae). Bull. Entomol. Res. 2001; 91:265-272. [PubMed: 11587622] 
Casimiro S, Coleman M, Hemingway B, Sharp B. Insecticide resistance in Anopheles arabiensis and Anopheles gambiae from Mozambique. J. Med. Entomol. 2006a; 43:276-282. [PubMed: 16619611]

Casimiro S, Coleman M, Mohloai P, Hemingway J, Sharp B. Insecticide resistance in Anopheles funestus (Diptera: Culicidae) from Mozambique. J. Med. Entomol. 2006b; 43:267-275. [PubMed: 16619610]

Chandre F, Darriet F, Duchon S, Finot L, Manguin S, Carnevale P, Guillet P. Modifications of pyrethroid effects associated with $k d r$ mutation in Anopheles gambiae. Med. Vet. Entomol. 2000; 14:81-88. [PubMed: 10759316]

Chen H, Minakawa N, Beier J, Yan G. Population genetic structure of Anopheles gambiae mosquitoes on Lake Victoria islands, west Kenya. Malaria J. 2004; 3:48.

Chen H, Githeko A, Zhou G, Githure J, Yan G. New records of Anopheles arabiensis breeding on the Mount Kenya highlands indicate indigenous malaria transmission. Malaria J. 2006a; 5:17.

Chen H, Fillinger U, Yan G. Oviposition behavior of female Anopheles gambiae in western Kenya inferred from microsatellite markers. Am. J. Trop. Med. Hyg. 2006b; 75:246-250. [PubMed: 16896126]

Curtis CF, Miller JE, Hodjati MH, Kolaczinski JH, Kasumba I. Can anything be done to maintain the effectiveness of pyrethroid-impregnated bednets against malaria vectors? Phi. Trans. Roy. Soc.: Bio. Sci. 1998; 353:1769-1775.

Diabate A, Baldet T, Chandre F, Akogbeto M. The role of agricultural use of insecticides in resistance to pyrethroids in Anopheles gambiae s.l. in Burkina Faso. Am. J. Trop. Med. Hyg. 2002; 67:617622. [PubMed: 12518852]

Dong K. A single amino acid change in the para sodium channel protein is associated with knockdown-resistance (kdr) to pyrethroid insecticides in German cockroach. Insect Biochem. Mol. Bio. 1997; 27:93-100. [PubMed: 9066120]

Elissa N, Mouchet J, Riviere F, Meunier JY, Yao K. Resistance of Anopheles gambiae s.s to pyrethroids in Cote d'Ivoire. Ann. Soc. Belege. Med. Trop. 1993; 73:291-294.

GFATM. 2007. http://www.theglobalfund.org/en/about/malaria/

Greenwood B, Mutabingwa T. Malaria in 2002. Nature. 2002; 415:670-672. [PubMed: 11832954]

Guyatt HL, Noor AM, Ochola SA, Snow RW. Use of intermittent presumptive treatment and insecticide treated bed nets by pregnant women in four Kenyan districts. Trop. Med. Int. Health. 2004; 9:255-261. [PubMed: 15040563]

Hall TA. BioEdit: a user-friendly biological sequence alignment editor and analysis program for Windows 95/98/NT. Nucl. Acids. Symp. Ser. 1999; 41:95-98.

Hargreaves K, Koekemoer LL, Brooke BD, Hunt RH, Mthembu J, Coetzee M. Anopheles funestus resistant to pyrethroid insecticides in South Africa. Med. Vet. Entomol. 2000; 14:181-189. [PubMed: 10872862]

Hawley WA, Kuile FOT, Steketee RS, Nahlen BL, Terlouw DJ, Gimnig JE, Shi YP, Vulule JM, Alaii JA, Hightower AW, Kolczak MS, Kariuki SK, Phillips-Howard PA. Implicationa of the western Kenya permethrin-treated bed net study for policy, program implementation, and future research. Am. J. Trop. Med. Hyg. 2003; 68(4 suppl.):168-173. [PubMed: 12749501]

Hemingway J, Hawkes NJ, McCarroll L, Ranson H. The molecular basis of insecticide resistance in mosquitoes. Insect Biochem. Mol. Biol. 2004; 34:653-665. [PubMed: 15242706]

Hodjati M, Curtis CF. Pyrethroid resistance in Anopheles is age dependent. Ann. Trop. Med. Parasitol. 1996; 90:438.

Hunt RH, Brooke BD, Pillay C, Koekemoer LL, Coetzee M. Laboratory selection for and characteristics of pyrethroid resistance in the malarial vector Anopheles funestus. Med. Vet. Entomol. 2005; 19:271-275. [PubMed: 16134975]

Jamroz RC, Guerrero FD, Kammlah DM, Kunz SE. Role of the kdr and super-kdr sodium channel mutations in pyrethroid resistance: correlation of allelic frequency to resistance level in wild and laboratory populations of horn flies (Haematobia irritans). Insect Biochem Mol. Bio. 1998; 28:1031-1037. [PubMed: 9887519]

Kamau L, Vulule JM. Status of insecticide susceptibility in Anopheles arabiensis from Mwea rice irrigation scheme, Central Kenya. Malaria J. 2006; 5:46. 
Kulkarni MA, Rowland M, Alifrangis M, Mosha FW, Matowo J, Malima R, Peter J, Kweka E, Lyimo I, Magesa S, Salanti A, Rau ME, Drakeley C. Occurrence of the leucine-to-phenylalanine knockdown resistance $(k d r)$ mutation in Anopheles arabiensis populations in Tanzania, detected by a simplified high-throughput SSOP-ELISA method. Malaria J. 2006; 5:56.

Lehmann T, Licht M, Elissa N, Maega TA, Chimumbwa JM, Watsenga FT, Wondji CS, Simard F, Hawley WA. Population structure of Anopheles gambiae in Africa. J. Heredity. 2003; 94:133-147.

Lindblade KA, Gimnig JE, Kamau L, Hawley WA, Odhiambo F, Olang G, Ter Kuile FO, Vulule JM, Slutsker L. Impact of sustained use of insecticide-treated bednets on malaria vector species distribution and culicine mosquitoes. J. Med. Entomol. 2006; 43:428-32. [PubMed: 16619629]

Liu N, Xu Q, Zhu F, Zhang L. Pyrethroid resistance in mosquitoes. Insect Science. 2006; 13:159-166.

Martinez-Torres D, Chandre F, Williamson MS, Darriet F, Berge JB, Devonshire AL, Guillet P, Pasteur N, Pauron D. Molecular characterization of pyrethroid knockdown resistance $(k d r)$ in the major malaria vector Anopheles gambiae s.s. Insect Mol. Biol. 1998; 7:179-184. [PubMed: 9535162]

Matambo TS, Abdalla H, Brooke BD, Koekemoer LL, Mnzava A, Hunt RH, Coetzee M. Insecticide resistance in the malarial mosquito Anopheles arabiensis and association with the kdr mutation. Med. Vet. Entomol. 2007; 21:97-102. [PubMed: 17373952]

Mbogo CM, Mwangangi JM, Nzovu J, Gu W, Yan G, Gunter JT, Swalm C, Keating J, Regens JL, Shililu JI, Githure JI, Beier JC. Spatial and temporal heterogeneity of Anopheles mosquitoes and Plasmodium falciparum transmission along the Kenyan coast. Am. J. Trop. Med. Hyg. 2003; 68:734-42. [PubMed: 12887036]

Nevill CG, Some ES, Mung'ala VO, Mutemi W, New L, Marsh L, Lengeler C, Snow RW. Insecticidetreated bednets reduce mortality and severe morbidity from malaria among children on the Kenyan coast. Trop. Med. Int. Health. 1996; 1:139-146. [PubMed: 8665377]

Nyanjom SRG, Chen H, Gebre-Michael T, Bekele E, Shililu J, Githure J, Beier C, Yan G. Population genetic structure of Anopheles arabiensis mosquitoes in Ethiopia and Eritrea. J. Heredity. 2003; 94:457-463.

Pinto J, Lynd A, Elissa N, Donnelly MJ, Costa C, Gentile G, Caccone A, Do Rosario VE. Cooccurrence of East and West African $k d r$ mutations suggests high levels of resistance to pyrethroid insecticides in Anopheles gambiae from Libreville, Gabon. Med. Vet. Entomol. 2006; 20:27-32. [PubMed: 16608487]

Phillips-Howard PA, Nahlen BL, Kolczak MS, Hightower AW, Ter Kuile FO, Alaii JA, Gimnig JE, Arudo J, Vulule JM, Odhacha A, Kachur SP, Schoute E, Rosen DH, Sexton JD, Oloo AJ, Hawley WA. Efficacy of permethrin-treated bed nets in the prevention of mortality in young children in an area of high perennial malaria transmission in western Kenya. Am. J. Trop. Med. Hyg. 2003; 68(4 suppl.):23-29. [PubMed: 12749482]

Ranson H, Jensen B, Vulule JM, Wang X, Hemingway J, Collins FH. Identification of a point mutation in the voltage-gated sodium channel gene of Kenyan Anopheles gambiae associated with resistance to DDT and pyrethroids. Insect Mol Biol. 2000; 9:491-497. [PubMed: 11029667]

Scott JA, Brogdon WG, Collins FH. Identification of single specimens of the Anopheles gambiae complex by the polymerase chain reaction. Am. J. Trop. Med. Hyg. 1993; 49:520-529. [PubMed: 8214283]

Shanks GD, Hay SI, Omumbo JA, Snow RW. Malaria in Kenya western highlands. Emerging Infectious Diseases. 2005; 11:1425-1432. [PubMed: 16229773]

Sina BJ, Aultman K. Resisting resistance. Trends in Parasitol. 2001; 17:305-306.

Stump AD, Atieli FK, Vulule JM, Besansky NJ. Dynamics of the pyrethroid knockdown resistance allele in western Kenyan populations of Anopheles gambiae in response to insecticide-treated bed net trials. Am. J. Trop. Med. Hyg. 2004; 70:591-596. [PubMed: 15210997]

Temu E, Yan G. Microsatellite and mitochondrial genetic differentiation of Anopheles arabiensis (Diptera: Culicidae) from western Kenya, the Great Rift Valley, and coastal Kenya. Am. J. Trop. Med. Hyg. 2005; 73:726-733. [PubMed: 16222017]

Verhaeghen K, Van Bortel W, Roelants P, Backeljau T, Coosemans M. Detection of the East and West African kdr mutation in Anopheles gambiae and Anopheles arabiensis from Uganda using a new assay based on FRET/Melt Curve analysis. Malaria J. 2006; 5:16. 
Vulule JM, Beach RF, Atieli FK, Roberts JM, Mount DL, Mwangi RW. Reduced susceptibility of Anopheles gambiae to permethrin associated with permethrin-impregnated nets and curtains in Kenya. Med. Vet. Entomol. 1994; 8:71-75. [PubMed: 8161849]

Vulule JM, Beach RF, Atieli FK, Mount DL, Roberts JM, Mwangi RW. Long-term use of permethrinimpregnated nets does not increase Anopheles gambiae permethrin tolerance. Med. Vet. Entomol. 1996; 10:71-79. [PubMed: 8834745]

Vulule JM, Beach RF, Atieli FK, Mcallister JC, Brogdon WG, Roberts JM, Mwangi RW, Hawley WA. Elevated oxidase and esterase levels associated with permethrin tolerance in Anopheles gambiae from Kenyan villages using permethrin-impregnated nets. Med. Vet. Entomol. 1999; 13:239-244. [PubMed: 10514048]

Wiseman V, Hawley WA, Kuile FOT, Phillips-Howard PA, Vulule JM, Nahlen BL, Mills AJ. The cost-effectiveness of permethrin-treated bed nets in an area of intense malaria transmission in western Kenya. Am. J. Trop. Med. Hyg. 2003; 68:161-167. [PubMed: 12749500]

Williamson MS, Denholm I, Bell CA, Devonshire AL. Knockdown resistance (kdr) to DDT and pyrethroid insecticides maps to a sodium channel gene locus in the housefly (Musca domestica). Mol. Gen. Genet. 1993; 240:17-22. [PubMed: 8101963]

WHO. Global malaria control. Bull. WHO. 1993; 71:281-284. [PubMed: 8324845]

Yamey G. Roll Back Malaria: a failing global health campaign. Br. Med. J. 2004; 328:1086-1087. [PubMed: 15130956] 


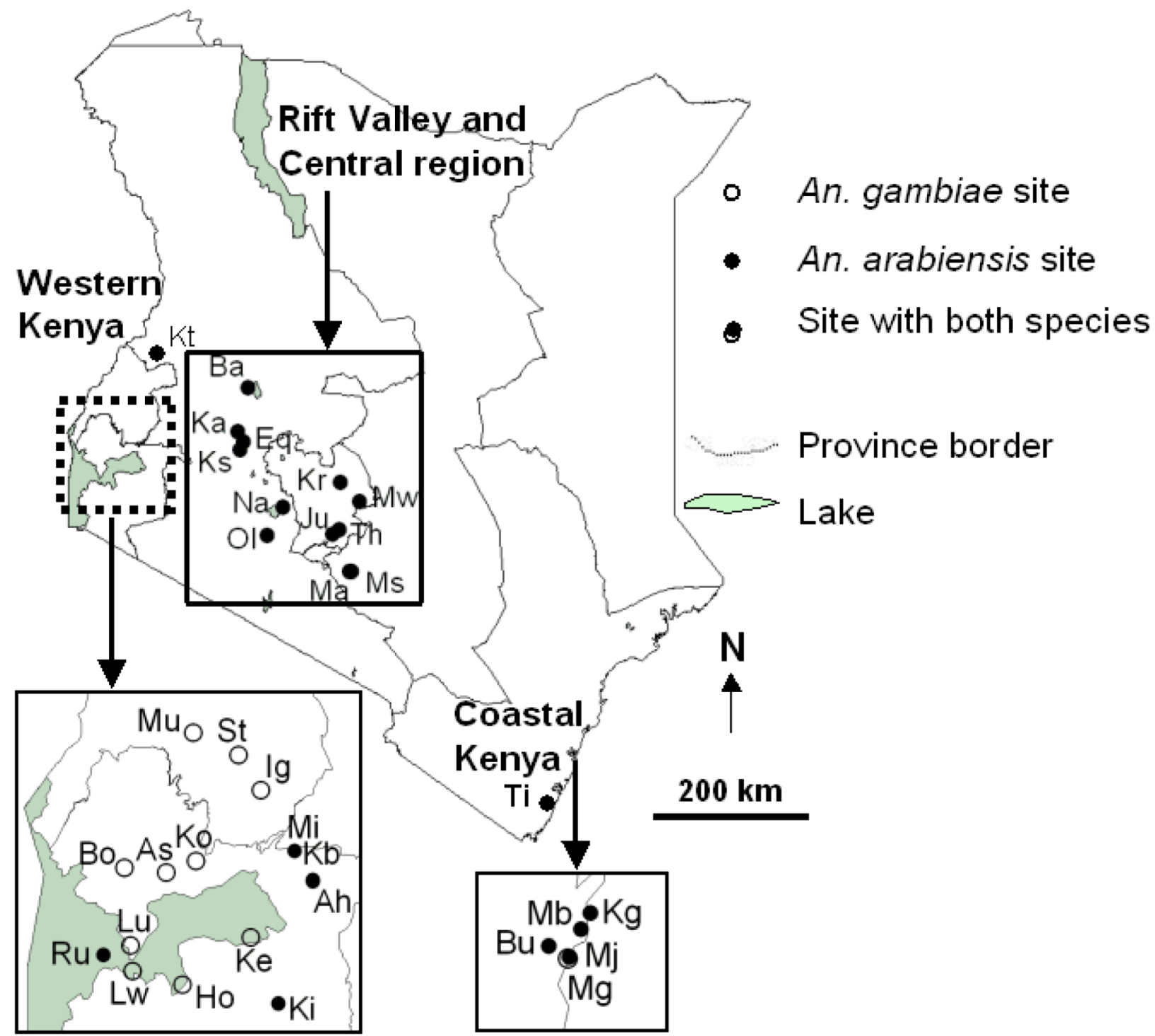

Fig. 1.

Schematic map of collection sites. Site codes are defined in Table 1. Circles and solid circles indicate the sites where at least 40 Anopheles gambiae and An. arabiensis larvae were collected, respectively. 


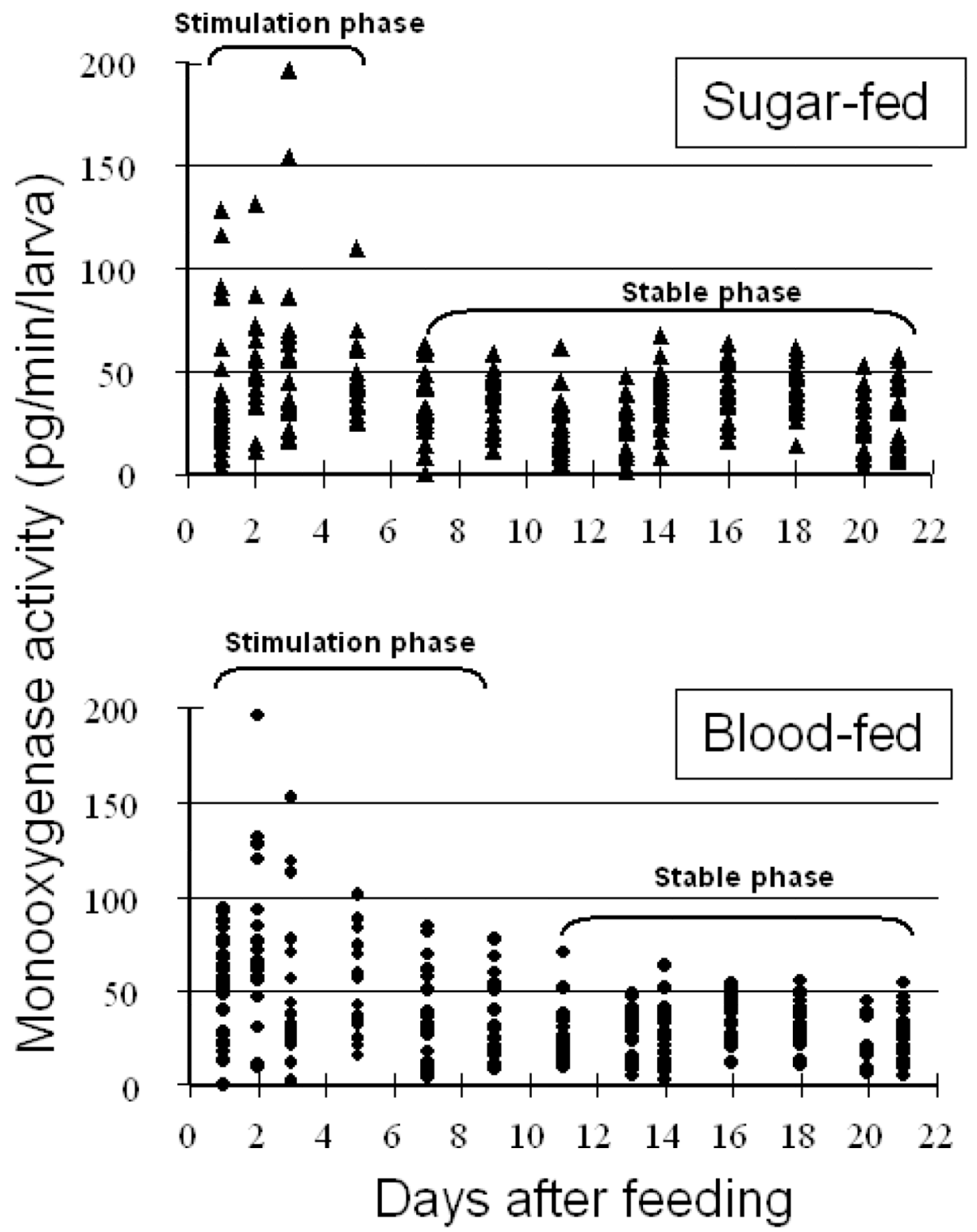

Fig. 2.

Dynamics of monooxygenase activity in sugar-fed and blood-fed Anopheles gambiae females. 

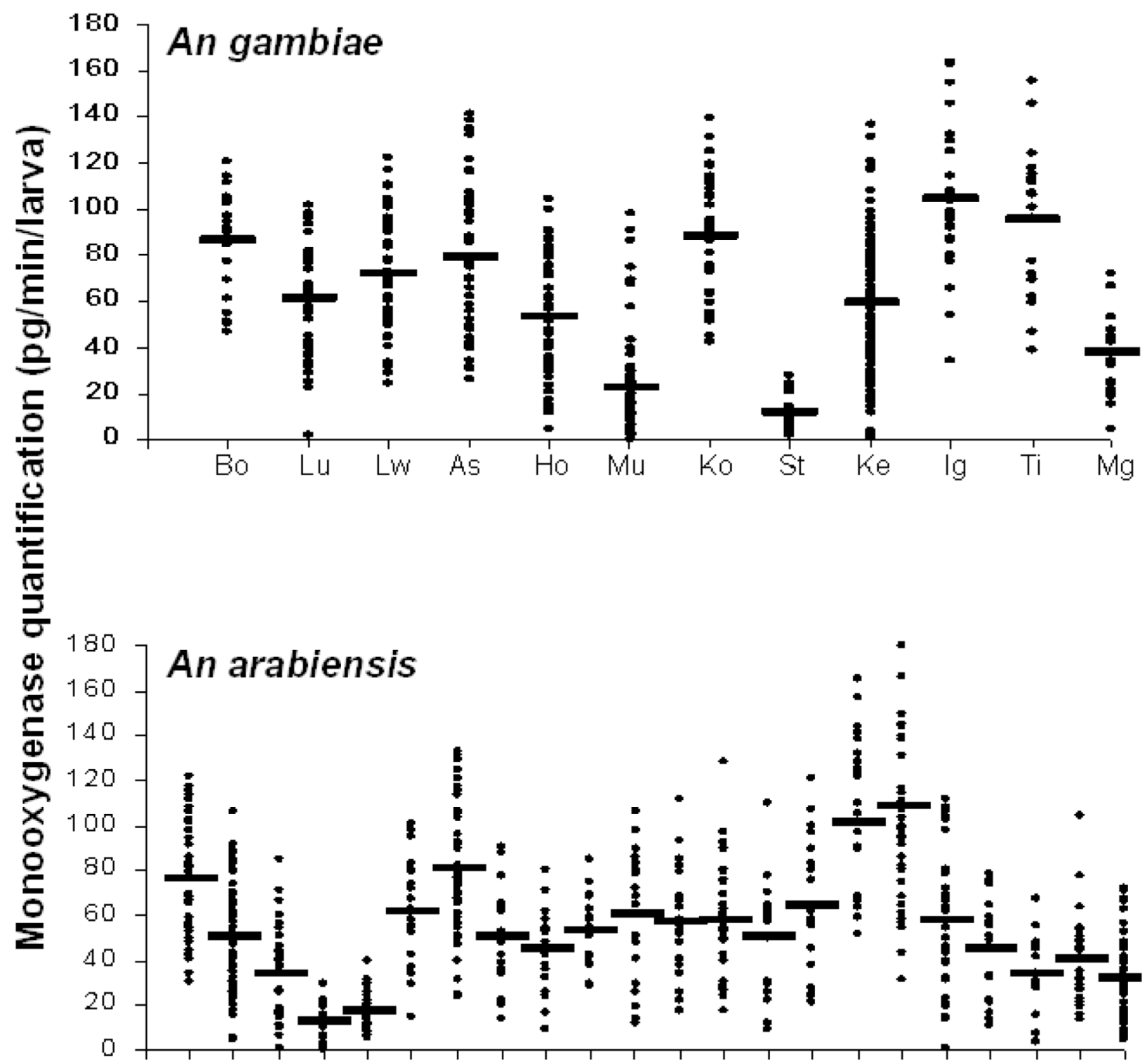

Ru Ki Mi Ah Kb Kt Ka Ks Eq Ba Ol Na JuTh Kr Ma Ms Mw Bu Mb Mj Kg

Fig. 3.

Monooxygenase levels in Anopheles gambiae and An. arabiensis populations. Site codes are defined in Table 1. Population means of enzyme activities are indicated by the bars. 
Table 1

A list of collection sites in Kenya, larval habitat types and sample size used in this study.

\begin{tabular}{|c|c|c|c|c|}
\hline Region & Site (abbreviation) & Types of larval sampling site & An. gambiae specimens & An. arabiensis specimens \\
\hline \multirow[t]{16}{*}{ Western } & Rusinga (Ru) & Small pounds & - & 40 \\
\hline & Bondo (Bo) & Swamp & 50 & - \\
\hline & Luanda $(\mathrm{Lu})$ & Swamp & 49 & - \\
\hline & Lwanda (Lw) & Swamp & 47 & - \\
\hline & Asembo (As) & Footprints & 50 & - \\
\hline & Homa Bay (Ho) & Small pounds and swamp & 50 & - \\
\hline & Mumias (Mu) & Small pounds & 67 & - \\
\hline & Kombewa (Ko) & Small pounds & 66 & - \\
\hline & Stendmwako (St) & Small pounds & 66 & - \\
\hline & Kendo $(\mathrm{Ke})$ & Small pounds & 90 & - \\
\hline & Iguhu (Ig) & Small pounds & 56 & - \\
\hline & Kisii (Ki) & Small pounds & - & 50 \\
\hline & Miwani (Mi) & Small pounds & - & 70 \\
\hline & Ahero (Ah) & Footprints & - & 54 \\
\hline & Kibigori (Kb) & Small pounds & - & 70 \\
\hline & Kitale (Kt) & Small pounds & - & 64 \\
\hline \multirow{12}{*}{$\begin{array}{l}\text { Rift Valley and } \\
\text { Central }\end{array}$} & Katheluny (Ka) & Swamp & - & 44 \\
\hline & Kibshana (Ks) & Big pounds & - & 52 \\
\hline & Equator (Eq) & Big pounds & - & 56 \\
\hline & Baringo (Ba) & Small pounds & - & 56 \\
\hline & Olasiti (Ol) & Small pounds & - & 60 \\
\hline & Naivasha (Na) & Small pounds & - & 60 \\
\hline & Juja (Ju) & Small pounds & - & 66 \\
\hline & Thika (Th) & Small pounds and swamp & - & 58 \\
\hline & Karatina $(\mathrm{Kr})$ & Small pounds & - & 58 \\
\hline & Machakos Stream (Ma) & Small pounds & - & 66 \\
\hline & Machakos Swamp (Ms) & Swamp & - & 80 \\
\hline & Mwea (Mw) & Footprints & - & 70 \\
\hline \multirow[t]{6}{*}{ Coastal } & Tiwi (Ti) & Swamp & 58 & - \\
\hline & Burangi (Bu) & Footprints & - & 56 \\
\hline & Malindi Green (Mg) & Swimming pool & 60 & - \\
\hline & Malindi Baob (Mb) & Swimming pool & - & 56 \\
\hline & Majejena (Mj) & Swamp & - & 50 \\
\hline & Kangombani (Kg) & Small pounds & - & 45 \\
\hline
\end{tabular}

“_" indicates that mosquito samples at a particular site were either not present or had insufficient numbers $(<40)$ for monooxygenase and $k d r$ analyses. 


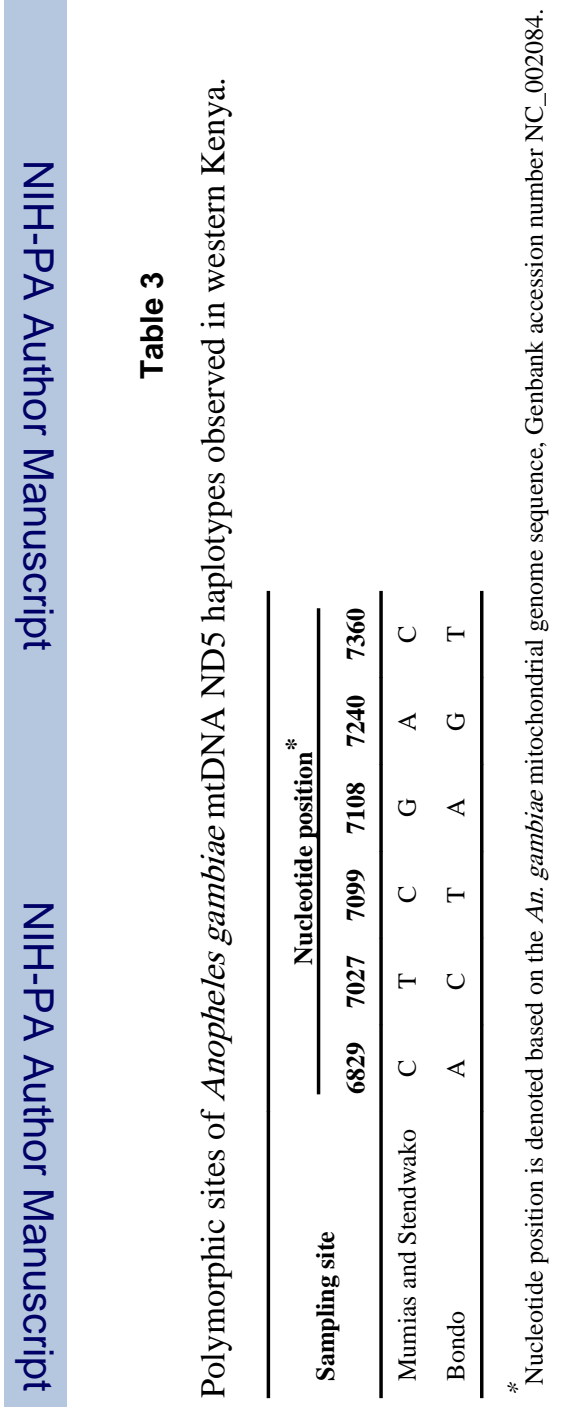

J Med Entomol. Author manuscript; available in PMC 2013 July 29. 